\title{
43. Critical Exposure Time to Estrogen for Cornification of Vaginal Epithelium in Spayed Rats
}

By Yasumasa Arai, Shizuko Momose, and Sakae MasudA

Department of Anatomy, Juntendo University School of Medicine, Tokyo

(Comm. by 'Teizo Ogawa, M. J. A., March 12, 1968)

It is well known that cornification of the vaginal epithelium is highly dependent upon the presence of estrogen in normal and ovariectomized rats (see, Allen et al., 1939; Burrow, 1949). The influence of estrogen on the vaginal epithelium is thought to be the results of the direct action of estrogen on the epithelial cells (Jensen and Jacobson, 1962). Recently we found that a non-steroidal antiestrogen, CN-55, 947, 27 ${ }^{1}$ inhibited effectively estrogen-induced vaginal cornification in ovariectomized rats when it was given at the same time as estrogen, but cornification of the vaginal epithelium could not be inhibited by CN when this antiestrogen given 24 hours after estrogen (Arai and Gorski, 1968). On the basis of these findings we attempted to study the minimal exposure time to estrogen needed for inducing vaginal cornification.

Two weeks after ovariectomy female rats of the Wistar strain weighing 180 to $240 \mathrm{~g}$ were used for the experiments. In general, estradiol benzoate (EB, $0.75 \mu \mathrm{g} / 0.1 \mathrm{ml}$ sesame oil) was given subcutaneously once in the morning (10-11 a.m.) and killed 48 hours later. $\mathrm{CN}\left(500 \mu \mathrm{g} / 2.0 \mathrm{ml}\right.$ aqueous vehicle) or aqueous vehicle ${ }^{2)}$ was given twice 24 hours apart by gavage according to the experimental designs (see Table I). In each animal vaginal smear was taken on the day of autopsy. The vaginae were fixed in Bouin's fluid and processed routinely for histologic study.

As shown in Table I, EB treatment alone (Group 1) resulted in massive cornification and marked proliferation of the vaginal epithelium (Fig. 1). In contrast, when two administrations (24 hours apart starting with the injection of $\mathrm{EB}$ ) of $\mathrm{CN}$ were superimposed on $\mathrm{EB}$ treatment (Group 2), proliferation of basal cells of the vaginal epithelium was markedly inhibited and cornification failed to occur (Fig. 2). The epithelium consisted of only 3-4 cell layers, the

1) $\mathrm{CN}-55,945,27: 1-[2-(p-[\alpha-(p-$ methoxyphenyl $)-\beta$ nitrostyryl $]$ phenoxy $)$ ethyl $]$ pyrolidine, monocitrate.

2) The aqueous vehicle was composed of $0.9 \% \mathrm{NaCl}, 0.4 \%$ polysorbate $80,0.5 \%$ carboxymethylcellulose and $0.9 \%$ benzylalcohol. 
Table I. Critical exposure time to EB for vaginal cornification determined by $\mathrm{CN}$ administration

\begin{tabular}{|c|c|c|c|c|c|}
\hline Group & $\begin{array}{c}\text { EB at time } \\
\text { zero }\end{array}$ & $\begin{array}{c}\text { Time of } \mathrm{CN} \\
\text { administration } \\
\text { (hours after EB) }\end{array}$ & \multicolumn{3}{|c|}{$\begin{array}{l}\text { Cornification of vaginal } \\
\text { epithelium }\end{array}$} \\
\hline 1 & $\mathrm{~EB}$ & None & $6 * *)$ & 0 & 0 \\
\hline 2 & $\mathrm{~EB}$ & Zero & 0 & 1 & 5 \\
\hline 3 & $\mathrm{~EB}$ & 3 & 0 & 7 & 0 \\
\hline 4 & $\mathrm{~EB}$ & 6 & 4 & 1 & $2^{* * *)}$ \\
\hline 5 & $\mathrm{~EB}$ & 12 & 7 & 0 & 0 \\
\hline 6 & None & None & 0 & 0 & 4 \\
\hline
\end{tabular}

appearance of squamous cell layer being rare (1/6). The effect of CN was not as marked when this antiestrogen was given at 3 hours after EB, but the epithelium still contained no cornified cells. Moderate proliferation of the basal cells and hypertrophy of old superficial cells were observed and the development of eosinophilic squamous cell layers ${ }^{3)}$ was striking. It appeared as a clear stripe interposed between old superficial cell and polyhedral cell layers.

In the rats of Group 4 which received CN at 6 hours after EB, $\mathrm{CN}$ was no longer effective in preventing the occurrence of vaginal cornification. Complete vaginal cornification and marked proliferation of the epithelium were encountered in 3 out of 7 rats (Fig. 3). Their vaginal histology was virtually the same as that of the rats which received $\mathrm{EB}$ alone (Group 1). Localized cornification was observed in the vaginal epithelium of 1 animal. In the remaining 3 rats, the vaginal epithelium was thick and covered with denucleated squamous cells (1 rat) or mucified cells (2 rats), although cornification was not observed. When the administration of $\mathrm{CN}$ was delayed until 12 hours (Group 5), the effect of CN completely disappeared, well differentiated, thick, cornified epithelium being observed in all animals of the group.

The mechanism of the inhibitory action of $\mathrm{CN}$ is still unknown in the present study. Since CN inhibits the action of estrogen on the uterus apparently by blocking its uptake (Callantine et al., 1966), it might exert a similar effect in the vagina, perhaps at the level of the epithelial cells.

In the present study, the induction of cornification could not be inhibited by $\mathrm{CN}$ when given 6 hours after EB. It is suggested that the length of exposure time to EB needed for vaginal cornification

3) This layer consisted of denucleated cells or cells with flattened nucleus. 

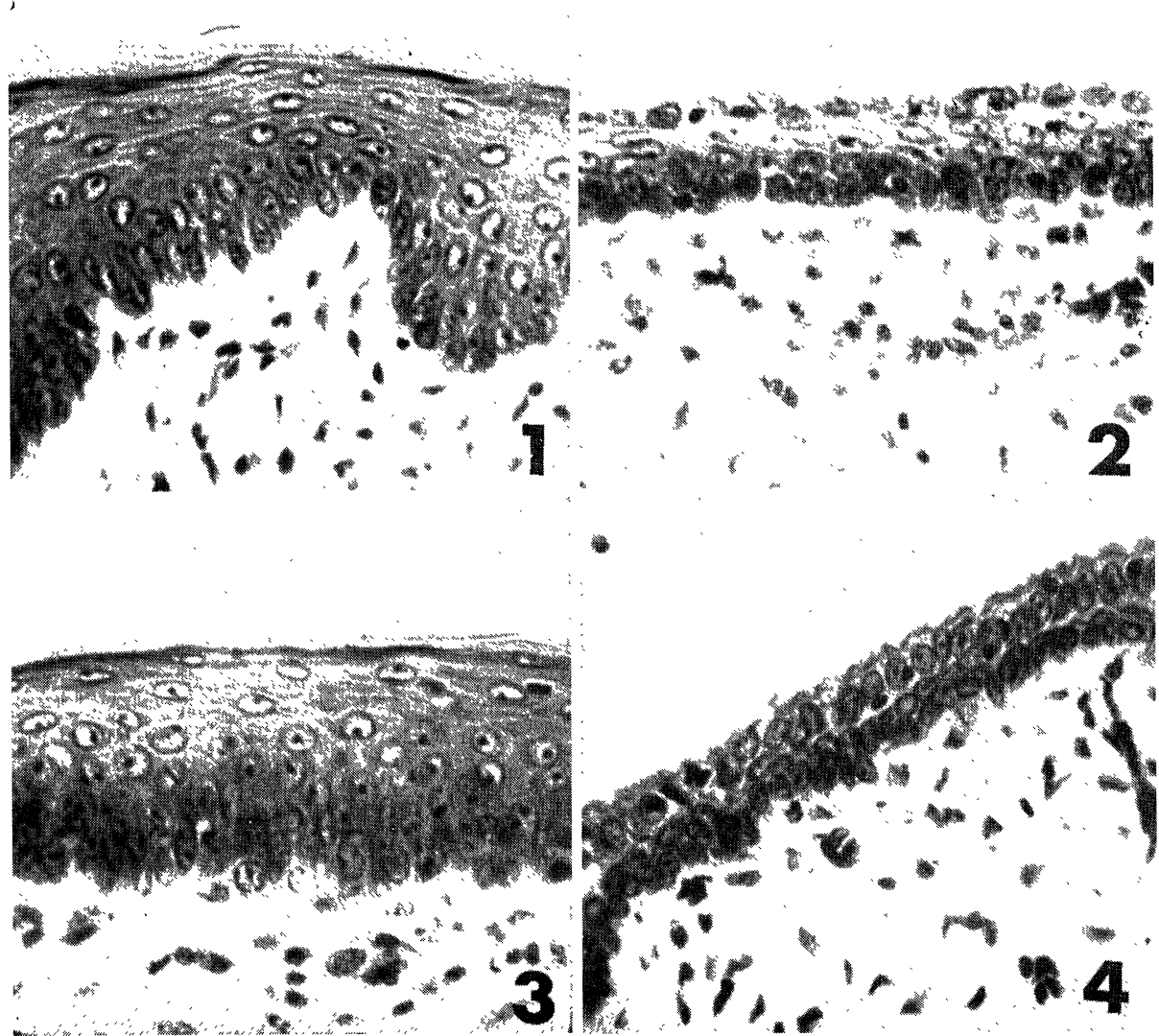

Fig. 1. Vagina of rat treated with EB alone. Note well differentiated, cornified epithelium.

Fig. 2. Vagina of rat treated with $\mathrm{EB}$ and $\mathrm{CN}$ at the same time. Note atrophic epithelium.

Fig. 3. Vagina of rat treated with $\mathrm{CN} 6$ hours after EB. Note thick, cornified epithelium.

Fig. 4. Vagina of ovariectomized rat without the treatment. Note atrophic epithelium.

is less than 6 hours. This conception is in harmony with the findings of Hori and Miyake (1966) that estrogen stimulated vaginal TTC $^{4)}$ reduction (supposed to be an earlier transient phenomenon in the process of vaginal cornification) was markedly inhibited by an antiestrogen, MER-25, when administered simultaneously with estrogen, but the inhibition was abolished when MER-25 given 6 hours after estrogen. Cornification of the vaginal epithelium did not appear yet 24 hours after EB (preliminary observation). Beyond a critical exposure, more time is necessary to develop the process

4) TTC: 2, 3, 5-triphenyltetrazolium chloride. 
of vaginal cornification. However, this process requires time during which the continued presence of estrogen, at least in the blood, might not be essential. It would appear that $\mathrm{CN}$ antagonizes only the early stage of this complex process.

The authors express their gratitude to Dr. H. A. DeWald of Parke, Davis Research Laboratories, U.S.A. for supplying the CN and to Dr. M. Sawai of Chemical Laboratories, Teikoku Hormone Mfg, Co., Ltd. for the aqueous vehicle and EB. We are also grateful to Dr. T. Kimura, University of Tokyo, for valuable suggestions.

\section{References}

Allen, E., Hisaw, F. L., and Gardner, W. U. (1939): In Sex and Internal Secretions. 2nd ed. Ed. E. Allen p. 452, Williams and Willkins Co., Baltimore.

Arai, Y., and Gorski, R. A. (1968): Physiol. Behav., 3 (in press).

Burrow, H. (1949): Biologic Actions of Sex Hormone. 2nd ed. Cambridge Univ. Press, London.

Callantine, M. R., Humphrey, R. R., and Nesset, B. L. (1966): Endocrinology, 79, 455.

Jensen, E. V., and Jacobson, H. I. (1962): Recent Prog. Hormone Res., 18, 387. Hori, T., and Miyake, T. (1966): Endocrinol. Japon., 13, 193. 